\title{
INSTABILITY OF THE GLOBAL GREENHOUSE GAS SYSTEM AS A CAUSE OF THE ICE AGES: A LOW-ORDER DYNAMICAL MODEL
}

\section{(Abstract)}

by

B. Saltzman and K.A. Maasch

(Department of Geology and Geophysics, Yale University, P.O.6666, New Haven, CT 06511, U.S.A.)

Due to the extremely low rate at which the major glacial variations occurred during the Pleistocene it is not possible to explain these variations by direct calculation of the fundamental fluxes of heat, momentum, and water mass that must be involved. Instead, we approach the problem in a more inductive manner by trying to formulate a physically plausible dynamical system, representing the net effects of these fluxes, that can account for the observed variance with a minimum number of adjustable parameters, given the known forcing due to Earth-orbital (Milankovitch) variations. Our model involves three "slow-response" variables: the global ice mass, the concentration of atmospheric greenhouse gases (notably $\mathrm{CO}_{2}$, methane, and water vapor), and a measure of the thermal-biologicalchemical state of the ocean (perhaps measured by the stratification) that may control the Earth's carbon cycle over the Pleistocene time period. These variables are connected by a nonlinear dynamical system comprised of three ordinary differential equations that can exhibit instability and free oscillatory behavior of a period close to 100000 years (the period at which the maximum ice-age variability is found to exist in the late Pleistocene) despite relatively small external Earth-orbital forcing. We calculate the rate constants needed for the model to account for the main features of the ice variations, including the mid-Pleistocene transition from a period of low global ice mass devoid of the 100000 year oscillation. The implied variations of the greenhouse gases over the past 150000 years are in good agreement with the recent Vostok ice-core analyses.

\section{A 3500-YEAR ICE CHEMISTRY RECORD FROM THE DOMINION RANGE, ANTARCTICA: LINKAGES BETWEEN CLIMATIC VARIATIONS AND PRECIPITATION CHEMISTRY}

\author{
(Abstract) \\ Mary Jo Spencer, Paul A. Mayewski, W. Berry Lyons, Mark S. Twickler \\ (Glacier Research Group, Institute for the Study of Earth, Oceans, and Space, \\ University of New Hampshire, Durham, NH 03824, U.S.A.) \\ and \\ Pieter Grootes \\ (Quaternary Research Center, University of Washington, Seattle, WA 98195, U.S.A.)
}

In 1984 a $200-\mathrm{m}$ ice core was collected from a local accumulation basin in the Dominion Range, Transantarctic Mountains, Antarctica. A complete oxygen isotope record has been obtained and a considerable portion of the core has been analyzed in detail for chloride, nitrate, sulfate, and sodium. About half of the chloride is due to sea salt with the remainder originating as gaseous $\mathrm{HCl}$. Nitrate levels have increased markedly over the last 1000 years whereas the levels of the other constituents have remained fairly constant.
The oxygen isotope results suggest that this region of Antarctica is responding to long-term global climate forcing as well as to shorter-term climatic variations. This data will be compared with the anion and sodium records in order to determine the effects of climatic forcing on these other records. In particular, nitrate appears to vary in concert with fluctuations in long-term climate. Additionally, variations in each constituent over the 3500 year period will be examined in detail to determine the influence of other processes which affect their concentrations. 